\title{
Journal of Inorganic and General Chemistry
}

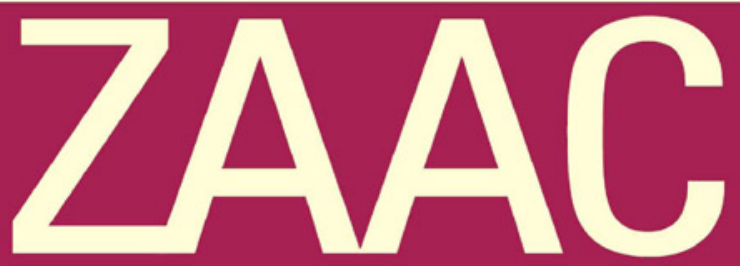

\section{Zeitschrift für anorganische und allgemeine Chemie}

\section{Accepted Article}

Title: Synthesis, performance and thermal behavior of a novel insensitive EDNA/DAT cocrystal

Authors: Ahmed K. HUSSEIN, Svatopluk ZEMAN, and Ahmed Elbeih

This manuscript has been accepted after peer review and appears as an Accepted Article online prior to editing, proofing, and formal publication of the final Version of Record (VoR). This work is currently citable by using the Digital Object Identifier (DOI) given below. The VoR will be published online in Early View as soon as possible and may be different to this Accepted Article as a result of editing. Readers should obtain the VoR from the journal website shown below when it is published to ensure accuracy of information. The authors are responsible for the content of this Accepted Article.

To be cited as: Z. anorg. allg. Chem. 10.1002/zaac.201800041

Link to VoR: http://dx.doi.org/10.1002/zaac.201800041 


\title{
Synthesis, performance and thermal behavior of a novel insensitive EDNA/DAT co-crystal
}

\author{
Ahmed K. HUSSEIN ${ }^{[a]}$, Svatopluk ZEMAN ${ }^{[a]}$, Ahmed ELBEIH ${ }^{\star[b]}$ \\ a Institute of Energetic Materials, Faculty of Chemical Technology, University of Pardubice, Czech Rep \\ ${ }^{b}$ Military Technical College, Kobry Elkobbah, Cairo, Egypt
}

\begin{abstract}
Due to the acidity and the limited applications of of 1,4dinitro-1,4-diazabutane (EDNA). A novel nitrogen rich energetic cocrystal based on EDNA and 1,5 diaminotetrazole (DAT) in a 1:2 molar ratio was synthesized. The formation of the co-crystal was tested by Scanning electron microscope (SEM), powder X-ray diffraction (PXRD) and Raman spectroscopy. Based on the elemental analysis and the enthalpy of combustion obtained by the calorimetric bomb, the enthalpy of formation was calculated to be $196.9 \mathrm{~kJ}^{\mathrm{mol}}{ }^{-1}$. Sensitivity to impact was measured and 50\% probability of initiation was $9.7 \mathrm{~J}$ for the co-crystal. In addition, the detonation characteristics were predicted by EXPLO5 Code. The detonation velocity $(\mathrm{D})$ and the detonation pressure $(\mathrm{P})$ of the cocrystal are $8254.5 \mathrm{~m} \mathrm{~s}^{-1}$ and $26.7 \mathrm{GPa}$ respectively. The thermal behavior and decomposition kinetics of the co-crystal and the coformer were described using nonisothermal differential scanning calorimetry (DSC) and thermogravimetry/differential thermogravimetry (TG/DTG) techniques. There is an obvious difference between the thermal behavior of the co-crystal and the coformer. The activation energy of the co-crystal $\left(125.3 \mathrm{~kJ} \mathrm{~mol}^{-1}\right)$ is lower than the coformer. The obtained co-crystal has high nitrogen content and acceptable sensitivity to external stimuli which possess it to be a promising for expanding the reuse of EDNA in ammunition after overcomeing its acidity problem.
\end{abstract}

\section{Introduction}

Energetic materials; explosives, propellants and pyrotechnics, are used for a variety of military purposes and civilian applications ${ }^{[1]}$. However, there are unacceptable explosive characteristics when using single crystal explosive materials, among them: low performance, high sensitivity to external stimuli, the insufficient physical properties of some explosives. Consequently, programs have been established worldwide to develop novel energetic materials with higher potential energy and enhanced insensitivity by synthesizing new energetic materials, preparing nanoscale particles of explosives ${ }^{[2]}$ or

\footnotetext{
[a] Ahmed K. Hussein, Svatopluk Zeman. Institute of Energetic Materials, Faculty of Chemical Technology University of Pardubice, CZ-532 10 Pardubice Czech Republic
}

[b] Ahmed Elbeih Military Technical College, Kobry Elkobbah, Cairo, Egypt adding insensitive compounds such as; phlagmatized explosives, mixutre of explosives ${ }^{[3 a, 3 b]}$ or coatings by polymers "PBX" [4a, 4b, 4c]. However, all the previously mentioned method can't optimize between the main characteristics; high performance, thermodynamic stability and low sensitivity [5]. Recently, new approach has been introduced "Co-crystal technique" which succeeds to combine coformers "different explosive materials" with each other. This technique is one of the main types of superamolecules which based on the intermolecular interaction as hydrogen bond, bi-stacking, van der Waals forces and halogen bonds ${ }^{[5 b]}$. This intermolecular interaction (Co-crystal) can connect two different molecules together in one crystal form, which can improve the solubility, performance and sensitivity ${ }^{[6]}$. These technique had been announced in pharmaceutical systems, it had been succeed with different drugs to improve the bioavailability and the solubility ${ }^{[7]}$. It was also passed down to energetic materials science and different publication were studied theoretically and were performed experimentally by combining two different energetic materials, as an example; CL-20 co-crystals ${ }^{[8]}$, TNT co-crystal [8c, 9] and HMX co-crystal [8a, 9b, 10] or with inert material such as; CL20/ caprolactam ${ }^{[10 a]}$ and other more.

1,5-diaminotetrazole (DAT) (shown in Fig: 1.a) is one of the family of Tetrazoles which are the core of aza in the heterocyclic compounds. The high positive enthalpies of formation and high nitrogen content of tetrazoles have made their complexes interesting for energetic materials investigation and research topics. They are involved in new researches focused on reducing impact on environment and synthesized green energetic materials ${ }^{[11]}$. They are heterocyclic compounds rich in electron pairs, and can coordinate with transition-metal ions. These compounds are thermally stable and yield a large volume of gas on thermal decomposition, so as to be used as prospective gas-generating, blowing agents for polymeric systems and other combustible and thermally decomposition systems. DAT is one of the organic compounds, which has high content of nitrogen $(84.0 \%)^{[12]}$, it has a positive heat of formation $\left(310.37 \mathrm{~kJ} \mathrm{~mol}^{-1}\right)$, its density is $1.75 \mathrm{~g}^{-\mathrm{cm}^{-3}}$, and the detonation velocity is $7570 \mathrm{~m} . \mathrm{s}^{-1}[13]$. It has a unique structure and remarkable properties; It is used in key intermediate in many organic synthesis, the medicinal and biological applications.

1,4-dinitro-1,4-diazabutane (EDNA) also known as Haleite [14] (shown in fig. 1.b) was first described as high explosive which was used during the WorldWar II in antitank ammunitions. It was used also in different application as secondary explosive, booster explosive and in the preparation of cast explosives such as ednatol (55\% EDNA + 45\% TNT). It has very interesting properties, possessing a high brisance, 
comparatively low impact sensitivity and high heat sensitivity. In contradiction with the above mentioned properties, there is a problem using EDNA as it has a high chemical acidic reactivity that drawback its chemical instability. EDNA is highly acidic (pK $\mathrm{a} 1=5.31$ and $\mathrm{pK}$ a2 $=6.64)^{[15]}$. It is corrosive and can react with metals and metal salts ${ }^{[14]}$. In this study, we describe the use of co-crystallizations to change the acidic affinity of EDNA by stabilization using the DAT and consequently increase the durability of EDNA in different applications by adding the high nitrogen content heterocyclic DAT.<smiles>Nc1nnnn1N</smiles>

(a)<smiles>O=[N+]([O-])NCCN[N+](=O)[O-]</smiles>

(b)
Figure 1: Chemical structures of a) DAT and b) EDNA

\section{Results and Discussion}

\subsection{Powder XRD}

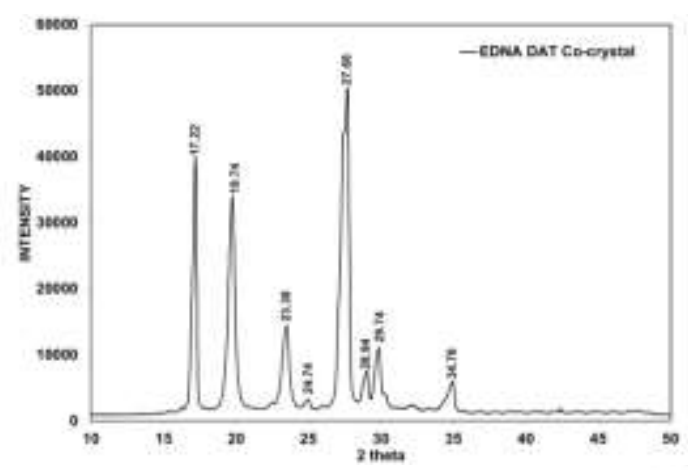

a. EDNA/DAT Co-crystal

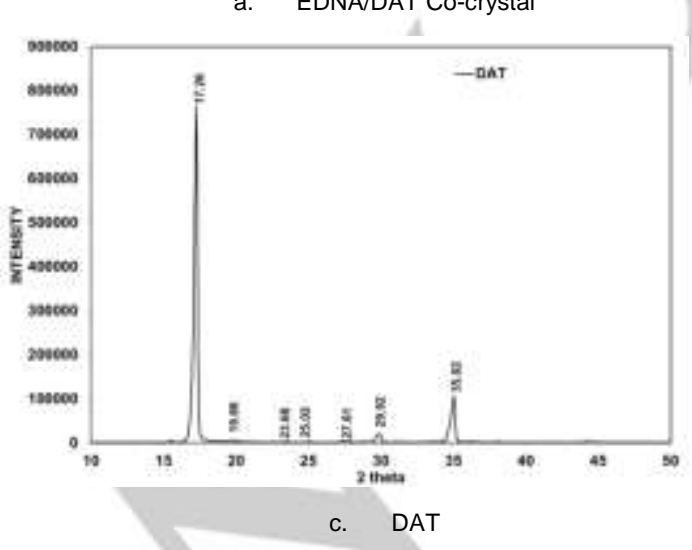

Figure 2: A comparison of powder XRD Spectra for a. EDNA/DAT Co-crystal, EDNA/DAT Mixture, c. DAT and d. EDNA.
According to the small size of the co-crystal sample and the limited features of the available single crystal XRD, the cocrystal was measured by powder XRD. Comparing the XRD results of the co-crystal with the pure coformer, it has been confirmed that the formed co-crystal is different from its components. By comparing XRD spectra with the Mixture, it can be found that mixture is combing the XRD peaks of pure EDNA and DAT and different from EDNA/DAT co-crystal which gave another confirmation of the formation of the co-crystal. The XRD patterns are shown in Figure 2. The main diff raction angles of the EDNA/DAT co-crystal localized at $34.78^{\circ}, 29.74^{\circ}, 27.66^{\circ}$, $23.38^{\circ}, 19.74^{\circ}$, and $17.22^{\circ}$ are evidently different from the raw materials EDNA and DAT and their mixture. In the $2 \theta$ range of $10-40$, some of the peaks for EDNA and DAT have disappeared, such as the peaks at $35.02^{\circ}, 25.02^{\circ}$ for DAT and $16.44^{\circ}, 26.3^{\circ}$, $30.08^{\circ}, 33.38^{\circ}, 35.06^{\circ}, 37.78^{\circ}, 42.6^{\circ}$ of EDNA and new peaks localized at $34.78^{\circ}, 27.66^{\circ}$ and $24.74^{\circ}$ are observed in the diff raction pattern of the co-crystal when compared with the PXRD pattern of the Mixture. These differences enable easy distinction between the co-crystal and pure raw DAT or EDNA, as shown in Figure 2. The unique XRD patterns of the co-crystal indicate that it is a new substance instead of the separate crystallization of the raw materials

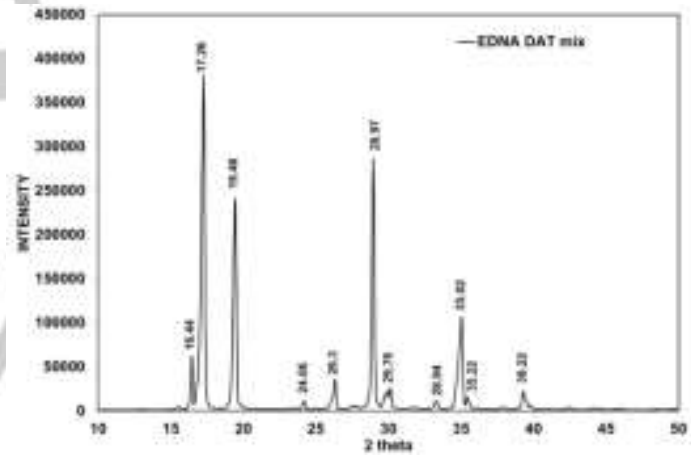

b. EDNA/DAT Mixture

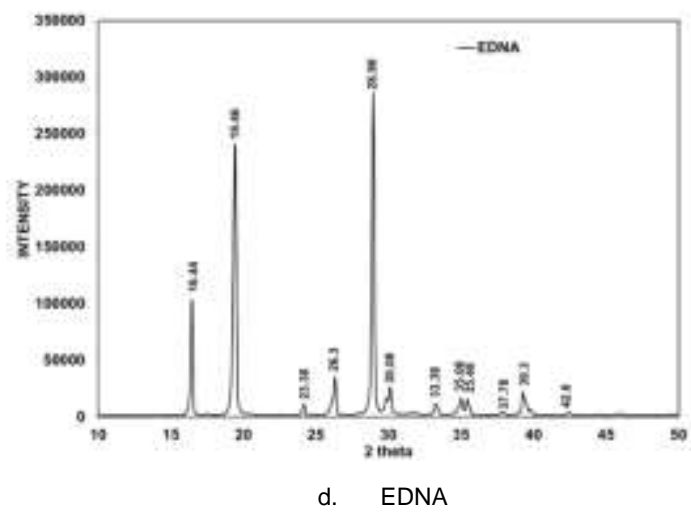

ת




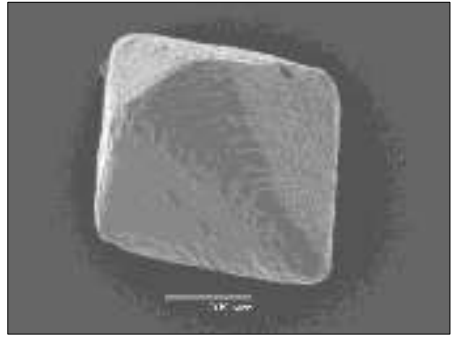

(a)

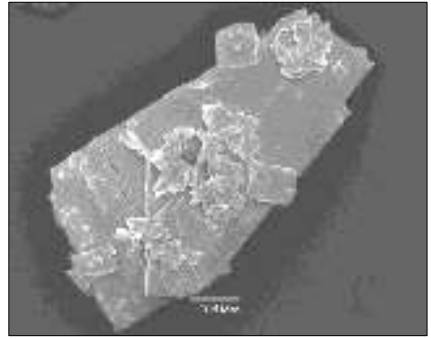

(b)

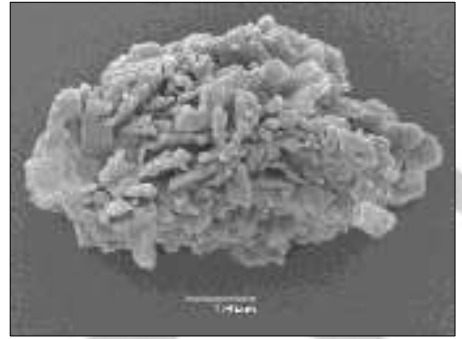

(c)

Figure 3: SEM image of a. EDNA crystal, b. DAT crystal and c. EDNA/DAT Co-crystal

\subsection{SEM}

The SEM images of coformer EDNA, DAT, and their co-crystal are shown in Figure 3. In Figure 3 (a), the morphology of raw EDNA particles presents the shape of polyhedron with uneven distribution, and the average particle size is about $100 \mu \mathrm{m}$. Raw DAT sample particles in Figure $3(\mathrm{~b})$ are plates and have a rough surface. The average particle size is about $300 \mu \mathrm{m}$. While in Figure 3(c), the co-crystal micro-particles obtained are amorphous within range from $50 \mu \mathrm{m}$ to $100 \mu \mathrm{m}$ in size

\subsection{Raman spectroscopy}

Raman spectroscopy is another useful method for the characterization of the co-crystal that shows that the vibrational modes of the co-crystal are different from those of the starting materials.

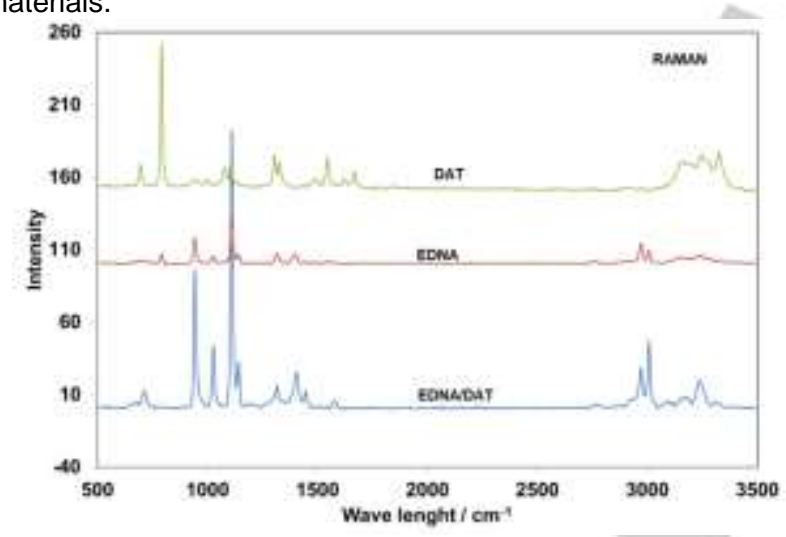

Figure 4 Raman Spectrum of EDNA/DAT co-crystal

A full understanding of the eff ects of the co-crystal formation on the vibrational modes of motion is obtained by the complete assignment of the spectra of the starting materials and of the cocrystal. The Raman spectra of raw EDNA, DAT, and the cocrystal are shown in Figure 4. While a comparison of the spectra are presented in Table 1. The results show certain shift in the band of the co-crystal compared with the coformer which lead for another confirmation about the formation of the co-crystal.

\subsection{Performance results}

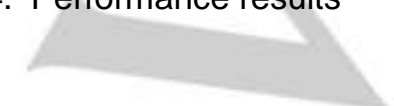

The explosives characteristics were calculated by the EXPLO5 program and listed in Table 2 after the calculation of heat of formation and the data exist from the elemental analysis.

From the obtained data, the positive heat of formation and high nitrogen percentage of the coformer DAT provide a positive influence on the performance characteristics of the produced cocrystal EDNA/DAT. The detonation velocity of the EDNA/DAT co-crystal is $8254.5 \mathrm{~m} . \mathrm{s}^{-1}$ and the detonation pressure is 26.7 GPa which are slightly lower than of EDNA but it is much higher than DAT.

\subsection{Impact sensitivity}

The impact sensitivity of the involved materials has been tested by BAM fall hammer method. Each test includes 5 impact energy levels and each level repeated 10 times, from which the probability will be calculated. The impact curves obtained for the EDNA/DAT co-crystal and the DAT compound are shown in Figure 5.

Table 1 RAMAN of EDNA, DAT and their cocrystsal:

\begin{tabular}{lcc}
\hline EDNA & Co-crystal & DAT \\
\hline 3240 & 3326 & 3325 \\
3008 & 3247 & 3249 \\
2972 & 3008 & 3160 \\
1447 & 2970 & 1669 \\
1405 & 1668 & 1546 \\
1317 & 1549 & 1329 \\
1142 & 1400 & 1306 \\
1111 & 1315 & 1106 \\
1028 & 1145 & 1079 \\
943 & 1112 & 792 \\
713 & 1027 & 697 \\
& 944 & \\
& 792 & \\
& 698 &
\end{tabular}

According to the impact data which was calculated at $50 \%$ probability of initiation, the sensitivity of the co-crystal to impact is $9.7 \mathrm{~J}$ which is much lower than the pure DAT $(15.4 \mathrm{~J})$. This result might reflect the effect of EDNA on the sensitivity behavior of the co-crysral. The impact sensitivity of the co-crystal is almost similar to the impact sensitivity of the well-known explosive Hexanitrostilbene (HNS) ${ }^{[16]}$. 
Table 2: Explosive characteristics and physical properties of EDNA, DAT and their EDNA/DAT cocrystsal

\begin{tabular}{|c|c|c|c|c|c|c|c|c|c|}
\hline $\begin{array}{l}\text { Explosive } \\
\text { designation }\end{array}$ & Formula & $\begin{array}{l}\text { Molecular } \\
\text { weight } \\
\left(\mathrm{g} \cdot \mathrm{mol}^{-1}\right)\end{array}$ & $\begin{array}{c}\text { Heat of } \\
\text { combustion } \\
\text { kJ.mol-1 }\end{array}$ & $\begin{array}{c}\begin{array}{c}\text { Heat of } \\
\text { formation }\end{array} \\
\text { kJ.mol-1 }\end{array}$ & $\begin{array}{l}\text { Density } \\
\text { g.cm }{ }^{-3}\end{array}$ & $\begin{array}{c}\text { Det. } \\
\text { Velocity } \\
\text { calculated } \\
\mathrm{m} . \mathrm{s}^{-1}\end{array}$ & $\begin{array}{l}\text { Det. } \\
\text { Pressure } \\
\text { calculated } \\
\text { GPa }\end{array}$ & $\begin{array}{c}\text { Impact } \\
\text { sensitivity } \\
\text { (J) }\end{array}$ & $\mathbf{N} \%$ \\
\hline DAT & $\mathrm{C}_{1} \mathrm{H}_{4} \mathrm{~N}_{6}$ & 100.1 & $1276.6^{[17]}$ & $310.4^{[17]}$ & $1.57^{[17]}$ & $7570.0^{[13]}$ & 20.7 & 15.4 & 84.0 \\
\hline $\begin{array}{c}\text { EDNA/DAT } \\
\text { Co-crstal }\end{array}$ & $\mathrm{C}_{3.88} \mathrm{H}_{13.63} \mathrm{~N}_{15.3} \mathrm{O}_{3.9}$ & 337.1 & 2747.6 & 196.9 & 1.73 & 8254.5 & 26.7 & 9.7 & 54.8 \\
\hline
\end{tabular}

DAT

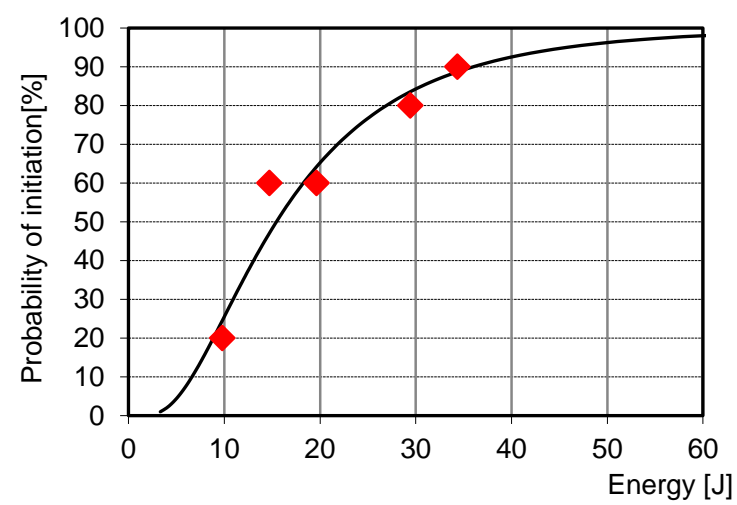

(a)

EDNA / DAT Co-crystal

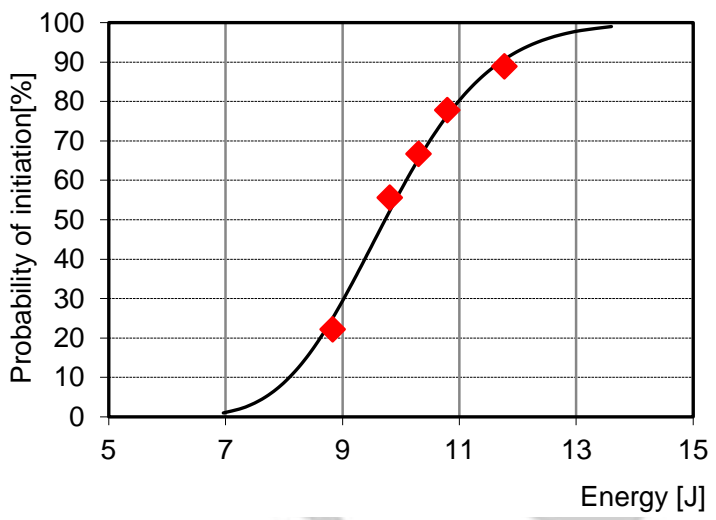

(b)

Figure 5: The impact sensitivity curves of a.DAT and b EDNA/DAT co-crystal

\subsection{Thermal analysis of the co-crystal and the coformer}

In our study to compare the heat change during the thermal decomposition of the co-crystal and the coformer, The DSC curves have been studied under the heating rate of $5.0^{\circ} \mathrm{C} \mathrm{min}{ }^{-1}$ as shown in Figure 6 . The parameters are summarized in
Table 3. It was evident from the curves that the thermal behavio of co-crystal is obviously diff erent from their coformers, and the differences in thermal stability of these substances further suggest of the formation of a new crystal.

Table 3. Results of non-isothermal DSC data of EDNA, DAT, and the cocrystal at $5^{\circ} \mathrm{C} \mathrm{min}^{-1}$ heating rate

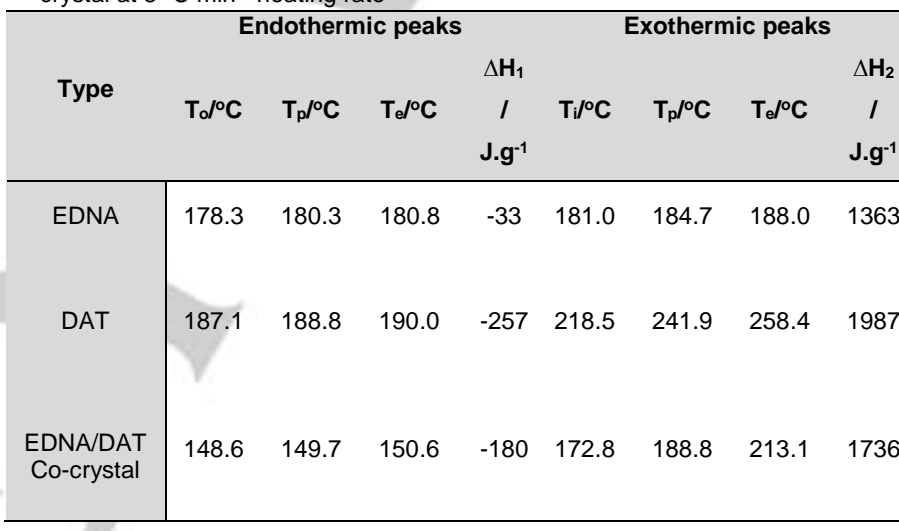

Note: the $T_{0}$, the onset temperature of the peaks; $T_{p}$, the maximum peak Temperature; $T_{e}$, the end temperature for the heat change; $\Delta \mathrm{H}_{1}, \Delta \mathrm{H}_{2}$, the heat absorbed, the heat released for the studied sample respectively.

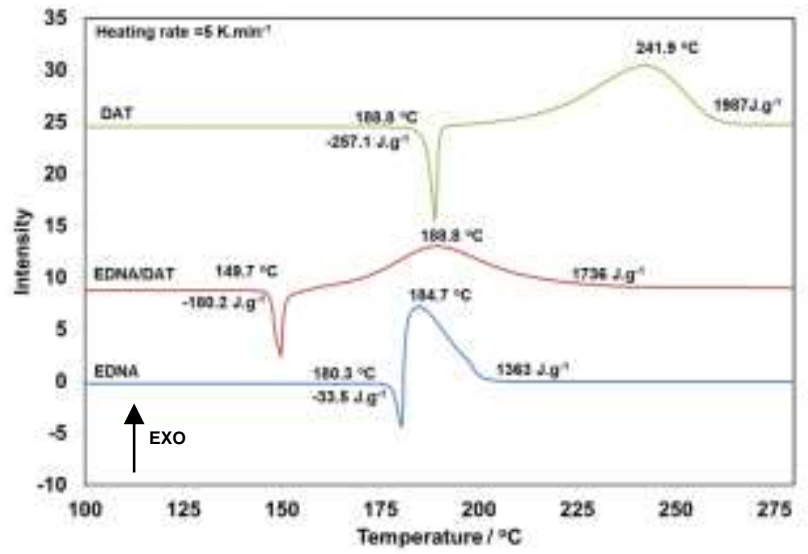

Figure 6: DSC curves for EDNA, DAT and their co-crystal at heating rate of $5^{\circ} \mathrm{C} \mathrm{min}^{-1}$

For the studied co-crystal, the exothermic peaks at $5{ }^{\circ} \mathrm{C} \cdot \mathrm{min}^{-1}$ are well formed; indicating signs of kinetically controlled decomposition processes. In addition it can be seen that both the endothermic and exothermic peak are shifted to lower temperature. 


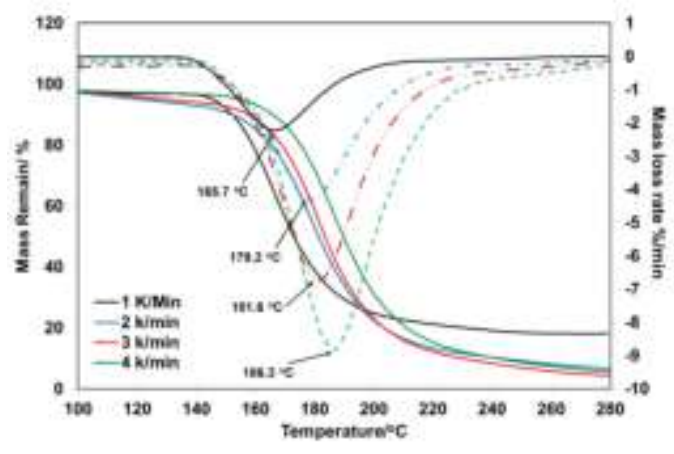

a EDNA/DAT co-crystal

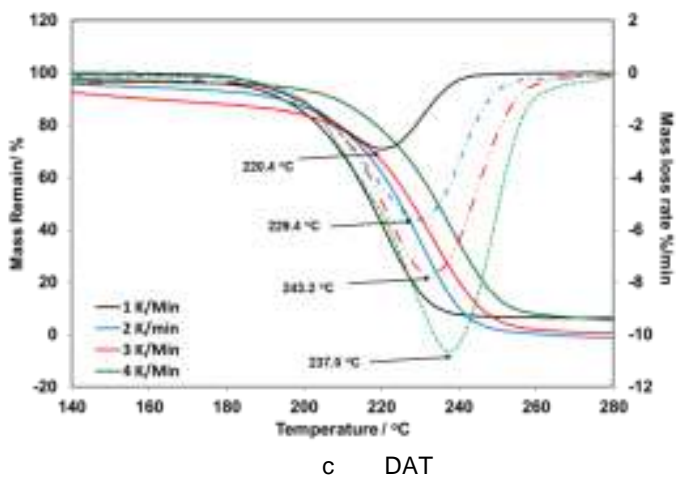

Table 4. Results of non-isothermal TG/DTG of the co-crystal EDNA/DAT

\begin{tabular}{|c|c|c|c|c|c|c|}
\hline \multirow[b]{2}{*}{ type } & \multicolumn{3}{|c|}{ TG curve } & \multicolumn{3}{|c|}{ DTG curve } \\
\hline & ${ }^{\circ} \mathrm{C} \frac{\min }{1}-$ & $\begin{array}{c}\mathbf{T}_{0} \\
/ \\
\circ \mathbf{C}\end{array}$ & $\begin{array}{c}\text { Mass } \\
\text { loss } \\
/ \\
\% \\
\end{array}$ & $\begin{array}{c}L_{\max } \\
/ \\
\% . \min ^{-1}\end{array}$ & $\begin{array}{c}\mathrm{T}_{\mathrm{p}} \\
/ \\
{ }^{\circ} \mathrm{C}\end{array}$ & $\begin{array}{c}\mathrm{T}_{\mathrm{oe}} \\
/ \\
{ }^{\circ} \mathrm{C}\end{array}$ \\
\hline \multirow{4}{*}{$\begin{array}{l}\text { Co-crystal } \\
\text { EDNA/DAT }\end{array}$} & 1.0 & 153.1 & 76.68 & -2.2 & 165.7 & 190.8 \\
\hline & 2.0 & 154.9 & 81.75 & -4.3 & 179.2 & 202.1 \\
\hline & 3.0 & 163.9 & 84.29 & -6.76 & 181.6 & 204.6 \\
\hline & 4.0 & 172.9 & 89.76 & -8.8 & 186.3 & 208.4 \\
\hline \multirow{4}{*}{ DAT } & 1.0 & 201.9 & 88.94 & -2.98 & 220.4 & 238.2 \\
\hline & 2.0 & 211.1 & 93.62 & -5.46 & 229.4 & 249.8 \\
\hline & 3.0 & 216.4 & 86.52 & -8.48 & 243.2 & 253.2 \\
\hline & 4.0 & 219.6 & 80.68 & -10.47 & 237.0 & 257.0 \\
\hline \multirow{4}{*}{ EDNA } & 1.0 & 177.7 & 93.18 & -21.02 & 179.7 & 182.6 \\
\hline & 2.0 & 178.0 & 96.51 & -27.18 & 181.5 & 186.1 \\
\hline & 3.0 & 179.8 & 97.38 & -32.30 & 183.7 & 190.6 \\
\hline & 4.0 & 181.0 & 98.32 & -38.71 & 185.3 & 193.6 \\
\hline
\end{tabular}

$\beta$, the heating rate; $T_{0}$, onset temperature of the decomposition; $L_{\max }$, the maximium mass loss rate, $T_{p}$; the peak temperature of mass loss rate; $T_{o e}$, onset temperature of the end decomposition

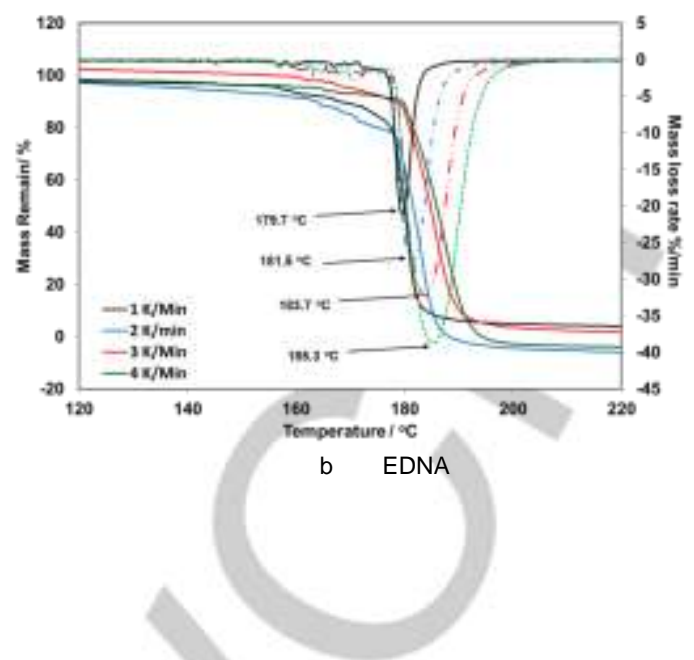

Figure 7 Non-isothermal TG/DTG of the co-crystal of EDNA/DAT and coformers EDNA, DAT at 1, 2, 3 and $4{ }^{\circ} \mathrm{C} \mathrm{min}^{-1}$ heating rate.

The EDNA/DAT co-crystal shows melting at $149.7^{\circ} \mathrm{C}$ with a decrease about $30^{\circ} \mathrm{C}$ comparing with EDNA, which can be attributed to effect of the formation of new material. Also, it can be observed that the enthalpy of the co-crystal for both the endothermic and exothermic peaks are of average value between the enthalpies of the coformer. TG/DTG curves of the EDNA, DAT and EDNA/DAT co-crystal under the heating rates of $1,2,3$ and $4{ }^{\circ} \mathrm{C} \cdot \mathrm{min}^{-1}$ were recorded. Results of the nonisothermal measurements of the co-crystal are presented in table 4 and The TG/DTG curve is shown in Figure .7. It has shown that the only single decomposition process has been observed which indicate behavior as single crystal. The characteristic parameters of the TG and DTG curves of the cocrystal are summarized on Table 4. It was shown from the onset temperature of thermal decomposition and initial mass loss temperature increase with the heating rates

\subsection{Estimation of the decomposition Kinetics:}

According to the recommendation of International Confederation of Thermal Analysis and Calorimetry (ICTAC) [19], the dependence of the activation energy on the degree of conversion, the modified Kissinger-Akahira-Sunose (KAS) isoconversional method was used for the studied sample. For this study, the activation energies at conversion rates from 5 to $90 \%$ were determined. However, it is recommended to take the mean values at $\alpha$ interval from 0.3 to 0.85 due to the increased of inaccuracy from the tail peak of DTG. The calculated results are summarized in Table 5. 
Table 5. Kinetic parameters of EDNA, DAT and their co-crystal by modified isoconversional KAS method

\begin{tabular}{|c|c|c|c|c|c|c|c|c|c|}
\hline \multirow[b]{2}{*}{$\alpha$ reacted } & \multicolumn{3}{|c|}{ EDNA } & \multicolumn{3}{|c|}{ DAT } & \multicolumn{3}{|c|}{ EDNA/DAT co-crystal } \\
\hline & $\begin{array}{c}\mathrm{E}_{\mathrm{a}} \\
\mathrm{kJ} \cdot \mathrm{mol}^{-1}\end{array}$ & $\log _{s^{-1}} A$ & $\mathrm{R}^{2}$ & $\begin{array}{c}\mathrm{E}_{\mathrm{a}} \\
\mathrm{kJ} \cdot \mathrm{mol}^{-1}\end{array}$ & $\underset{s^{-1}}{\log A}$ & $\mathrm{R}^{2}$ & $\begin{array}{c}\mathrm{E}_{\mathrm{a}} \\
\mathrm{kJ} \cdot \mathrm{mol}^{-1}\end{array}$ & $\log _{s^{-1}} A$ & $\mathrm{R}^{2}$ \\
\hline 0.05 & 581.1 & 78.7 & 0.9936 & 175.7 & 30.7 & 0.9625 & 159.0 & 30.52 & 0.9892 \\
\hline 0.10 & 578.8 & 78.4 & 0.9949 & 170.0 & 29.8 & 0.9965 & 131.8 & 26.93 & 0.9859 \\
\hline 0.15 & 517.4 & 71.2 & 0.9989 & 168.7 & 29.5 & 0.9986 & 144.1 & 28.29 & 0.9823 \\
\hline 0.20 & 501.3 & 69.2 & 0.9999 & 172.3 & 29.8 & 0.9978 & 136.2 & 27.23 & 0.9859 \\
\hline 0.25 & 460.8 & 64.5 & 0.9999 & 161.9 & 28.6 & 0.9936 & 129.4 & 26.33 & 0.9858 \\
\hline 0.30 & 431.1 & 61.0 & 0.9996 & 163.5 & 28.7 & 0.9993 & 130.0 & 26.33 & 0.9862 \\
\hline 0.35 & 404.4 & 57.9 & 0.9987 & 164.9 & 28.8 & 0.9993 & 131.2 & 26.41 & 0.9862 \\
\hline 0.40 & 379.9 & 55.0 & 0.9969 & 166.2 & 28.8 & 0.9993 & 123.8 & 25.48 & 0.9843 \\
\hline 0.45 & 357.5 & 52.4 & 0.9956 & 160.2 & 28.1 & 0.9965 & 124.9 & 25.54 & 0.9841 \\
\hline 0.50 & 337.6 & 50.1 & 0.9968 & 161.5 & 28.2 & 0.9965 & 126.0 & 25.62 & 0.9843 \\
\hline 0.55 & 322.0 & 48.2 & 0.9962 & 152.3 & 27.2 & 0.9933 & 121.3 & 24.99 & 0.9804 \\
\hline 0.60 & 284.6 & 43.8 & 0.9819 & 153.3 & 27.2 & 0.9997 & 122.5 & 25.07 & 0.9804 \\
\hline 0.65 & 267.8 & 41.8 & 0.9741 & 154.2 & 27.3 & 0.9933 & 123.6 & 25.14 & 0.9804 \\
\hline 0.70 & 254.4 & 40.3 & 0.9737 & 155.5 & 27.4 & 0.9933 & 125.3 & 25.25 & 0.9804 \\
\hline 0.75 & 257.3 & 40.6 & 0.9893 & 156.5 & 27.4 & 0.9997 & 120.9 & 24.64 & 0.9830 \\
\hline 0.80 & 245.6 & 39.2 & 0.9892 & 148.4 & 26.5 & 0.9982 & 123.6 & 24.82 & 0.9873 \\
\hline 0.85 & 238.8 & 38.3 & 0.9853 & 149.6 & 26.6 & 0.9982 & 130.8 & 25.49 & 0.9620 \\
\hline 0.90 & 229.8 & 37.2 & 0.9809 & 151.4 & 26.7 & 0.9983 & 125.7 & 24.67 & 0.861 \\
\hline $\begin{array}{l}\text { Mean } \\
\text { value }\end{array}$ & $315.1 \pm 19.2$ & \multicolumn{2}{|c|}{$47.4 \pm 2.21$} & $157.2 \pm 1.7$ & \multicolumn{2}{|c|}{$26.6 \pm 0.54$} & $125.3 \pm 1.09$ & \multicolumn{2}{|c|}{$26.04 \pm 0.17$} \\
\hline $\mathrm{S}^{\neq} / \mathrm{JK}^{-1} \mathrm{~mol}^{-1}$ & \multicolumn{3}{|c|}{685.2} & \multicolumn{3}{|c|}{2758.7} & \multicolumn{3}{|c|}{2149.6} \\
\hline
\end{tabular}

* The mean value for the activation energy was taken from the range of $\alpha=0.25$ to 0.85 as it is the main decomposition peak of the studied materials

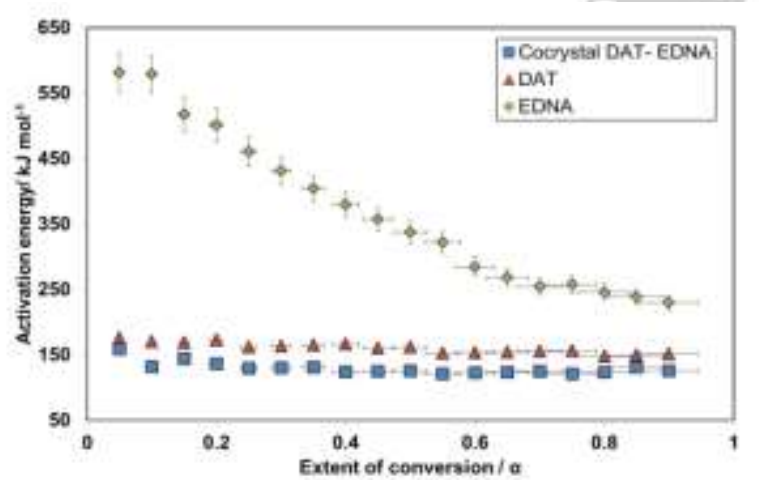

Figure 8: Dependence of activation energy of EDNA, DAT and their cocrystal on extent of conversion by isoconversional modified KAS method

For the EDNA thermal decomposition the temperature region of its melting point. Fig. 6 shows that decomposition reaction should be very high it is also indication of high values of Arrhenius parameters. From the literature, decomposition of EDNA in the solid state (temperature region 393-418 K) was studied by means of the Russian Manometric Method (RMM) with $\mathrm{E}_{\mathrm{a}}=186.2 \mathrm{~kJ} \mathrm{~mol}^{-1}$ and $\log \mathrm{A}=18.0^{[20]}$. Activation energies from the RMM aplication on the different tetrazole derivatives move in the range of $158-177 \mathrm{~kJ} \mathrm{~mol}^{-1}$ and corresponding logarithms of preexponents of 13.5-15.4 [21]. From comparing of these facts with results in Table 5 the relative real $E_{a}$ values for DAT and EDNA/DAT co-crystal are possible to obtain, but preexponents are fairly high. This might be due to the different applied technique of measurements. Therefore, another evaluation was obtained on the basis of calculated values of the activation entropy (see in Table 5). The obtained values indicating that it corresponds to very low molecular complexity (about this see also ${ }^{[22]}$ ) and primary step of decomposition of the coformers and co-crystal should be radical process. The comparison between the dependence of activation energy of EDNA, DAT and their co-crystal on the extent of conversion are also represented in Figure 8. From this relationship we can evaluate the tendency of the activation energy to be effective or composite value which help in making reliable kinetic prediction to have information about the mechanism of the decomposition. The full decomposition mechanism of the co-crystal will be discussed in more detail in further work.

For the DAT and the co-crystal, the activation energies are not dependent on temperature. It has different behavior compared with EDNA. 


\section{Conclusion}

Crystallization of the 1,4-dinitro-1,4-diazabutane (EDNA) and 1,5-diaminotetrazole (DAT) from acetonitrile, in the molar ration of $1: 2$, led to new co-crystal which was confirmed by the Powder XRD. The formed EDNA/DAT co-crystal has a promising detonation characteristics, the detonation velocities (D) and the detonation pressure $(\mathrm{P})$ are $8254.5 \mathrm{~m} \mathrm{~s}^{-1}$ and $26.7 \mathrm{GPa}$ respectively. It has good impact sensitivity of $9.7 \mathrm{~J}$ which in the level of $2,2^{\prime}, 4,4^{\prime}, 6,6^{\prime}$-hexanitrostilbene (HNS) and so is lower compared with the coformer EDNA. The thermal analysis of this co-crystal and its coformers, lead to high values of Arrhenius parameters of the EDNA decomposition $\left(E_{a}=315.1 \mathrm{~kJ} \mathrm{~mol}^{-1}\right.$ and $\log A=47.4$; which correspond to the temperature region of the EDNA melting point). While, the other values of activation energies are expectational, i.e. $E_{a}=157.2$ and $125.3 \mathrm{~kJ} \mathrm{~mol}^{-1}$ for DAT and EDNA/DAT respectively. Corresponding activation entropies show, that coformers and co-crystal should decompose by radical primary mechanism. This co-crystal possesses a promising future for expanding the reuse of EDNA, it might be used in ammunition because of overcoming the acidity problem. In addition, the higher nitrogen content and acceptable sensitivity to external stimuli.

\section{Experimental work}

\subsection{Materials and preparation of the co-crystal}

EDNA was prepared according to reference [23], DAT was obtained by a reaction of thiosemicarbazide, sodium azide, and lead oxide in dimethylformamide according to ref. ${ }^{[24]}$. Acetonitrile were purchased from Penta Reagent Factory, Czech Republic. The co-crystal was carried out by dissolving EDNA and DAT in molar ratio of $1: 2$ in Acetonitrile at $45{ }^{\circ} \mathrm{C}$ for 2 hours with constant stirring. After complete dissolving of the coformers. Ethanol was used as antislovent and used for precipitation at the same temperature. After that, the mixture of precipitate will be stirred for another hour during cooling and after the temperature decrease $d$ to normal temperature, filterating the new fine slightly yellow cocrystal and dried.

\section{2. powder X-ray diff raction (PXRD)}

The powder X-ray diff raction (PXRD) patterns were recorded to identify EDNA, DAT and the prepared co-crystal sample by sixth generation MiniFlex X-ray diffractometer (XRD), (Cu K $\beta, \lambda=$ $0.15406 \mathrm{~nm}, 40 \mathrm{kV}, 15 \mathrm{~mA}$, Miniflex, Rigaku, Japan). Images were integrated from 2 to 50 with a 0.05 step size using PDXL full-function powder diffraction analysis software suite.

\subsection{SEM and Raman spectroscopy}

The crystal morphology of the prepared co-crystal and the coformer were studied by scanning electron microscope (SEM) JSM-5500LV, JEOL, Japan. While, Raman spectra were measured with Nicolet Is50Raman, Thermo scientific, using an
Ar laser $(\lambda=514.5 \mathrm{~nm})$ and a semiconductor laser $(\lambda=785 \mathrm{~nm})$. The maximum output power is $1.7 \mathrm{~mW}$ of the light spot of the Raman spectrometer and the spectral resolution is $1 \mathrm{~cm}^{-1}$.

\subsection{Elemental Analysis}

Fisons - EA-1108 CHNS-O elemental analyzer was used for the determination of $\mathrm{C}, \mathrm{H}$, and $\mathrm{N}$ in the prepared co-crystal. The results of the elemental analysis were recalculated to match the nitrogen content to the individual explosive and reported in Table 1 as a hypothetical formula. By this way, the calculated formula was used as if it is individual explosive and it was used in the detonation parameters calculations.

\subsection{Heat of Combustion}

An automatic high pressure Bomb calorimeter, model BCA 500, OZM research s.r.o, Czech republic, was used to measure the heat of combustion of the co-crystal. The co-crystal was placed in a closed bomb filled with an excess of oxygen ${ }^{[25]}$ and ignited. The output data was used for calculation of the enthalpy of formation Table 1 of the co-crystal that was used for determining the detonation characteristics.

\subsection{Calculation of the detonation properties}

The theoretical detonation characteristics (detonation velocity, D, heat of detonation, $\mathrm{Q}$, and detonation pressure, $\mathrm{P}$ ) of the Cocrystal, as well as those of the individual explosives, were calculated by the EXPLO5 code version 5.04 [26]. The following Becker-Kistiakowsky-Wilson equation of state (BKW EOS) was used with BKWN set of parameters $\alpha=0.5, \beta=0.176, k=14.71$, $\Theta=662{ }^{[26]}$. The detonation heat is the heat released in a constant volume explosion and is determined by subtracting the heats of formation of the explosive (reactants) from the sum of the heats of formation of the detonation products. The theoretical calculation and the error between the experimental results are listed on Table 1

\subsection{Sensitivity to impact}

The standard impact tester with exchangeable drop weight of BAM impact sensitivity instrument ${ }^{[27]}$ was used ; the amount of substance tested was $50 \mathrm{~mm}^{3}$, and drop hammers of 2 and 5 $\mathrm{Kg}$ weight were used. The probability analysis was used to determine the probability levels of the initiation. Only the $50 \%$ probability of initiation $\left(\mathrm{H}_{50}\right)$ is used in this article and is reported in Table 1.

\subsection{Thermal analysis}

The co-crystal and the coformer were studied with regard to the kinetics of thermal decomposition, using different heating rate TG (Netzsch 209F3 instrument, $\mathrm{Al}_{2} \mathrm{O}_{3}$ crucible) and under a heating rate of $1,2,3$ and $4^{\circ} \mathrm{C} \cdot \mathrm{min}^{-1}$ (with data collecting rate of 40 points per Kelvin). The test temperature range for TG was $30-350{ }^{\circ} \mathrm{C}$, with the sample mass of about $2.0 \mathrm{mg}$ under 
$30 \mathrm{~mL} \mathrm{~min}^{-1}$ dynamic nitrogen atmosphere. Their heat flow properties were also evaluated by the technique of DSC (Netzsch 200F3 instrument, aluminum pan with a pin hole cover) which was introduced in the dynamic nitrogen atmosphere with a pressure of $0.1 \mathrm{MPa}$. The sample mass for DSC was about $2 \mathrm{mg}$ with heating rates of $2,5^{\circ} \mathrm{C} \mathrm{min}{ }^{-1}$ and temperature range of $40-$ $350^{\circ} \mathrm{C}$.

\section{Acknowledgements}

This paper was supported by means of the financial resources of Students Grant Projects No. SGSFCHT_2016002 of the Faculty of Chemical Technology at University of Pardubice.

Key words: EDNA, DAT, Co-crystal, sensitivity, thermal study.

[1] J. P. Agrawal, R. Hodgson, Organic chemistry of explosives, John Wiley \& Sons, 2007.

[2] D. Doblas, M. Rosenthal, M. Burghammer, D. Chernyshov, D. Spitzer, D. A. Ivanov, Crystal Growth \& Design 2015, 16, 432-439.

[3] aQ.-L. Yan, S. Zeman, P.E. Sánchez Jiménez, T.-L. Zhang, L.A. Pérez-Maqueda, A. Elbeih, Journal of Physical Chemistry C 2014, 118, 22881-22895; bV. Pelikán, S. Zeman, Q.-L. Yan, M. Erben, A. Elbeih, Z. Akštein, Central European Journal of Energetic Materials 2014, 11, 219-235.

[4] aA. Elbeih, T.Z. Wafy, T. Elshenawy, Central European Journal of Energetic Materials 2017, 14, 77-89; bA. Elbeih, S. Zeman, Central European Journal of Energetic Materials 2014, 11. 501-514; cA. Elbeih, M. Mokhtar Mohamed, T. Wafy, Propellants, Explosives, Pyrotechnics 2016, 41, 1044-1049.

[5] aE. Gagnière, D. Mangin, F. Puel, A. Rivoire, O. Monnier, E. Garcia, J.P. Klein, Journal of Crystal Growth 2009, 311, 2689-2695; bF. LaraOchoa, G. Espinosa-PÉRez, Supramolecular Chemistry 2007, 19, 553557; cJ. P. Shen, X. H. Duan, Q. P. Luo, Y. Zhou, Q. Bao, Y. J. Ma, C. H. Pei, Crystal Growth \& Design 2011, 11, 1759-1765; dD. D. Bavishi, C. H. Borkhataria, Progress in Crystal Growth and Characterization of Materials; eA. D. Bond, CrystEngComm 2007, 9, 833-834; fH.-H. Licht, Propellants Explosives Pyrotechnics 2000, 25, 126-132.

[6] D. D. Bavishi, C. H. Borkhataria, Progress in Crystal Growth and Characterization of Materials 2016, 62, 1-8.

[7] aP. Vishweshwar, J. A. McMahon, J. A. Bis, M. J. Zaworotko, Journal of pharmaceutical sciences 2006, 95, 499-516; bM. Nishimaru, S. Kudo, H. Takiyama, Journal of Industrial and Engineering Chemistry 2016, 36, 40-43.

[8] aO. Bolton, L. R. Simke, P. F. Pagoria, A. J. Matzger, Crystal Growth \& Design 2012, 12, 4311-4314; bH.-f. Gao, S.-h. Zhang, F. Liu, R.-j. Gou, X. Ding, Computational Materials Science 2015, 107, 33-41; cH. Li, Y. Shu, S. Gao, L. Chen, Q. Ma, X. Ju, Journal of molecular modeling 2013, 19, 4909-4917; dK. Liu, G. Zhang, J. Luan, Z. Chen, P. Su, Y. Shu, Journal of Molecular Structure 2016, 1110, 91-96; eD. I. Millar, H. E. Maynard-Casely, D. R. Allan, A. S. Cumming, A. R. Lennie, A. J. Mackay, I. D. Oswald, C. C. Tang, C. R. Pulham, CrystEngComm 2012 , 14, 3742-3749; fH. Xu, X. Duan, H. Li, C. Pei, RSC Advances 2015, 5, 95764-95770; gZ. Yang, H. Li, X. Zhou, C. Zhang, H. Huang, J. Li, F. Nie, Crystal Growth \& Design 2012, 12, 5155-5158.

[9] aC. Guo, H. Zhang, X. Wang, X. Liu, J. Sun, Journal of Materials Science 2013, 48, 1351-1357; bH. Li, C. An, W. Guo, X. Geng, J. Wang W. Xu, Propellants, Explosives, Pyrotechnics 2015, 40, 652-658.

[10] aC. Guo, H. Zhang, X. Wang, J. Xu, Y. Liu, X. Liu, H. Huang, J. Sun, Journal of Molecular Structure 2013, 1048, 267-273; bK. B. Landenberger, A. J. Matzger, Crystal Growth \& Design 2012, 12, 3603-
3609; cY.-x. Li, S.-s. Chen, Journal of molecular modeling 2015, 21, 112; dH. Lin, S. G. Zhu, L. Zhang, X. H. Peng, P. Y. Chen, H. Z. Li, International Journal of Quantum Chemistry 2013, 113, 1591-1599.

[11] Y. H. Joo, B. Twamley, J. n. M. Shreeve, Chemistry-A European Journal 2009, 15, 9097-9104.

[12] Y. Cui, J. Zhang, T. Zhang, L. Yang, J. Zhang, X. Hu, Journal of hazardous materials 2008, 160, 45-50.

[13] T. Konkova, Y. Matyushin, V. Sinditskiy, M. Dutov, A. Fogelzang, in INTERNATIONAL ANNUAL CONFERENCE-FRAUNHOFER INSTITUT FUR CHEMISCHE TECHNOLOGIE, Berghausen; Fraunhofer-Institut fur Chemische Technologie; 1999, 2000, pp. P88-P88.

[14] W. Tomlinson, O. Sheffield, Report AMCP 1971, 706-177.

[15] V. Ivshin, T. Ivshina, L. Smirnova, M. Ponomareva, ZHURNAL ORGANICHESKOI KHIMII 1984, 20, 7-13.

[16] S. N. Bulusu, Chemistry and physics of energetic materials, Vol. 309, Springer Science \& Business Media, 2012.

[17] M. Tremblay, Canadian Journal of Chemistry 1965, 43, 1154-1157.

[18] P. Tavernier, J. Boisson, B. Crampel, AGARD, 1970.

[19] S. Vyazovkin, A. K. Burnham, J. M. Criado, L. A. Pérez-Maqueda, C. Popescu, N. Sbirrazzuoli, Thermochimica Acta 2011, 520, 1-19.

[20] A. Pavlov, A. Fedotov, L. Pavlova, Y. V. Gamera, F. Dubovitskii, Kinetika khimicheskikh reaktsii 1989, 103.

[21] G. Manelis, Thermal decomposition and combustion of explosives and propellants, CRC Press, 2003.

[22] M. R. Wright, Introduction to chemical kinetics, John Wiley \& Sons, 2005.

[23] C. W. Sauer, Google Patents, 1958

[24] P. Gaponik, V. Karavai, Chemistry of Heterocyclic Compounds 1984, 20, 1388-1391.

[25] S. Fuels, Czech Institute of standards June 1999, Czech Tech Standard CSN ISO 1928.

[26] M. Sućeska, in Materials Science Forum, Vol. 465, Trans Tech Publ, 2004, pp. 325-330.

[27] S. Muhamed, Test methods for Explosives, Springer,, Heideleberg, 1995 